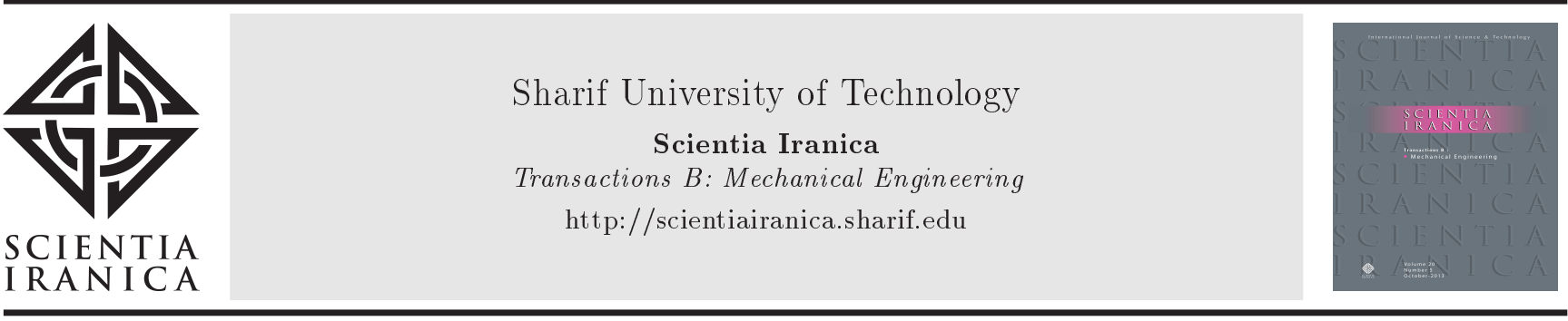

\title{
Boundary layer and surface pressure distribution behavior over a submarine nose model with two different nose shapes
}

\author{
A. Saeidinezhad ${ }^{a, *}$, A.A. Dehghan ${ }^{a}$, M. Dehghan Manshadi ${ }^{b}$ \\ a. Department of Mechanical Engineering, Yazd University, Daneshgah Boulevard, Safaeiyeh, Yazd, P.O. Box 89195-741, Iran. \\ b. Department of Mechanical and Aerospace Engineering, Malek Ashtar University of Technology, Esfahan, P.O. Box 83145-115, \\ Iran.
}

Received 24 February 2018; received in revised form 30 October 2018; accepted 26 January 2019

\author{
KEYWORDS \\ Nose shape; \\ Submarine model; \\ Boundary layer \\ properties; \\ Separation; \\ Wind tunnel.
}

\begin{abstract}
In this study, surface pressure distributions and boundary layer profiles were measured over the nose surface of a submarine model in a wind tunnel. The tests were conducted for two different nose shapes in order to study the effects of nose shape on the flow field around the model. The effect of Reynolds numbers, which are $0.5 \times 10^{6}, 0.8 \times 10^{6}$, and $10^{6}$, and pitch angles, $\alpha=0,5,10$, and $15^{\circ}$, on the surface pressure distribution over the surface of two nose shapes were investigated. Furthermore, the effects of the longitudinal pressure gradient on the boundary layer velocity profiles and the probability of separation on the plane of symmetry of the nose were studied. It was found that the Reynolds number did not have a significant effect on the nose surface pressure distribution at all pitch angles. The results showed that the presence of an adverse pressure gradient in the major portion of the blunter nose shape caused the non-dimensional velocity profiles of the boundary layer in $0.1 \leq X / L \leq 0.23$ locations to deviate from the log layer profile. Therefore, the separation on the blunter nose shape is more likely to occur than that on the other nose at high pitch angle manoeuvres.
\end{abstract}

(C) 2020 Sharif University of Technology. All rights reserved.

\section{Introduction}

The main body of airplanes, submarines, torpedoes, etc. with an axisymmetric nose is a body of revolution. The flow field over these bodies, especially their nose, presents motivating features due to the existence of both longitudinal and circumferential pressure gradients [1]. The variation of the boundary layer features (e.g., transition and separation) that are dependent

\footnotetext{
*. Corresponding author. Tel.: +983432230103 E-mail addresses: a.saeidinezhad@stu.yazd.ac.ir (A. Saeidinezhad); adehghan@yazd.ac.ir (A.A. Dehghan); mdmanshadi@mut-es.ac.ir (M. Dehghan Manshadi)
}

on the body shape and the pressure gradients may decrease the efficiency of such vehicles. For instance, the design of a submarine with higher speeds and lower noise levels needs a careful geometrical design. Improper body shape can cause extreme drag, noise, and instability [2]. In their recent study, Saeidinezhad et al. [3] investigated the hydrodynamic behavior of a submarine model with a non-axisymmetric nose in pitch manoeuvre. The measured drag coefficient of the model showed a nearly parabolic trend by increasing the pitch angle with a relatively high slope. In addition, their flow visualization result showed that the location of the flow separation for the nonaxisymmetric nose shape was closer to the nose tip than the symmetric nose at high angle of attack. Hence, the behavior of the drag coefficient versus 
pitch angle was attributed to the nose shape of the model.

A number of other experimental investigations have focused on flows over the bodies of revolution at incidence. Some of these research studies conducted a comprehensive investigation into the pressure distributions and boundary layer development on the surface of bodies of revolution [4]; however, few studies have investigated the details of the flow field around a submarine model, especially its nose.

Previous boundary layer research studies have mostly focused on the after-body part of the bodies of revolution, where the boundary layer has a thickness that is the same order of the local radius of the body [4]. Their results showed that transverse (or lateral) curvature affected the boundary layer behavior, which is usually neglected in the thin boundary layer theory. The boundary layer over a submarine rapidly thickens when the submarine moves on a straight line, while the boundary layer over the fore-body part of the submarine is still thin and can be treated by the conventional techniques [4].

Patel et al. [4] studied the pressure distributions, mean velocity profiles, and Reynolds stresses across the thick axisymmetric turbulent boundary layer near the tail of a six-to-one prolate spheroid model in a wind tunnel. Their result showed that the thick boundary layer was characterized by significant variations in static pressure across the layer, which is associated with a strong interaction between the boundary layer and the outside potential flow. Further, the low level of turbulence in the boundary layer was attributed to the transverse surface curvature.

Ramaprian et al. [5] and Patel and Baek [6] investigated the three-dimensional turbulent boundary layer on the plane of symmetry of a body of revolution (a hemispherical nose with a hemispheroidal rear) at an incidence angle of $15^{\circ}$. The surface pressure distributions were measured along the entire length of the body; however, the reliable distributions of the velocity vector of the boundary layer were measured at a longitudinal distance of $0.2 \leq X / L \leq 0.8$. The model was suspended stationary in the test section by wires, which were connected to the model nose and tail tip. The wires on the nose tip induced some disturbance in the velocity vectors in the distance range of $0 \leq X / L \leq 0.2$.

The results of Ramaprian et al. [5] exhibited the interaction between viscous and inviscid flows, cross-flow separation and formation of the longitudinal vortices in the boundary layer. The results of the study of Patel and Baek [6] identified the effect of the external flow convergence and/or divergence on the turbulence and the overall development of the boundary layer.

Groves et al. [7] designed and constructed an axisymmetric model called DARPA SUBOFF. This model was systematically tested to obtain the required experimental data in order to validate the results obtained from the numerical simulation. Huang and Liu [8] measured the pressure, velocity, skin friction, and Reynolds stress in the boundary layer of the stern region of the SUBOFF model with and without appendages in a wind tunnel. The results showed the effects of various appendages on the thick turbulent boundary layers over the stern. Many researchers have used the results of this work for validating numerical results. However, the flow field around the SUBOFF model nose has not been studied so far and needs a special consideration.

A review of the relevant literature shows that most of the experimental investigations measured the surface pressure, shear stress distributions, and boundary layer profiles along the mid-body and/or after-body of a body of revolutions equipped with a known nose shape; however, none of them investigated the effect of nose shape on the flow behavior around a submarine nose.

Javadi et al. [9] studied the effect of bow shapes (tango and standard bows) on the behavior of a submarine in the towing tank free-surface motion tests. In their previous works, Abedi et al. [10] and Saeidinezhad et al. [11] studied the separation and vorticity fields around a body of revolution at the incidence angle. Saeidinezhad et al. [11] investigated the effect of nose shape on the cross-flow separation and vortex formation around the SUBOFF submarine model by smoke and oil flow visualization methods. In addition, both longitudinal and circumferential surface pressure distributions on the submarine model with the two nose shapes at $\alpha=15^{\circ}$ were presented to support the nature of the flow structure and the separation patterns that were observed qualitatively in the flow visualization experiments.

The present work aims to study the boundary layer and surface pressure profile behavior measured along the nose of a submarine model on its symmetry plane for two different nose shapes and at various pitch angles. The main purpose of the present experiments is to investigate the effect of pressure gradient on the development of the boundary layer over a submarine nose. These results can give quantitative detailed data for the efficient design of a nose shape. This data can form a basis for further theoretical studies of the flow over the submarine models, especially two well-known submarine models: DARPA SUBOFF (Submarine model generated in Submarine Technology Program (STP) office of the Defence Advanced Research Project Agency of USA) and DRDC (Standard submarine model of Defence Research and Development Canada). The DRDC nose shape is blunter than the SUBOFF nose. In the present work, the effect of Reynolds numbers, i.e., $\operatorname{Re}=0.5 \times 10^{5}, 0.8 \times 10^{5}$, and $10^{6}$, and 
pitch angles, i.e., $\alpha=0,5,10$, and $15^{\circ}$, on the surface pressure distributions is studied in the case of two nose shapes. In addition, the velocity profile characteristics across the boundary layer, developed over these two nose shapes, are investigated at three pitch angles of $\alpha=0,5$, and $10^{\circ}$, and at $\operatorname{Re}=10^{6}$.

The present experimental tests are conducted in the wind tunnel. The captive model tests of an ocean vehicle are usually performed in a wind tunnel or within a towing tank apparatus. There are some differences between these two test environments. In the towing tank medium, all submersible conditions can be examined. The deep or semi-submersible tests of submersible models were performed in the towing tank [9,12-14]. Moreover, the resistance of the ship models was studied in a towing tank $[15,16]$. Wind tunnels do not have free surface and, therefore, only fully submerged conditions (such as immersed submarine) can be simulated $[3,8,17,18]$. Further, the sailboat study of the ships can be achieved in the wind tunnel and towing tank $[19,20]$. In experiments carried out on a submersible vehicle, two principal dimensionless numbers are Reynolds and Froude numbers. Javanmardi et al. [21] studied the effect of moving pressure source and channel parameters on the generated waves in a water channel, both numerically and experimentally. Their investigation showed that the generated wave height was independent of water depth for supercritical depth Froude numbers at a given Reynolds number. In addition, the blockage factor of water channel reportedly showed higher effect at supercritical Froude depth values, while it is negligible compared with water depth at subcritical Froude values. Since an underwater vehicle usually operates far away from the free surface, the Froude scaling is no longer considered and, thus, the most important similarity parameter for this case is the Reynolds number.

\section{Experimental setup}

\subsection{Wind tunnel and model}

The experiments in the present work are conducted in a closed-loop subsonic wind tunnel with a test section size of $370 \times 280 \times 1200 \mathrm{~mm}$. The axial fan of the tunnel provides airflow with the maximum speed of about $30 \mathrm{~m} / \mathrm{s}$ and a turbulence intensity level of $0.25 \%$ in the test section. The test section has 45-degree corner fillets that enlarge the cross-sectional area gradually in the downstream direction to maintain constant static pressure along the test section, therefore decreasing the buoyancy effects [22]. Figure 1 shows a schematic of the lower half part of the wind tunnel test section and the full shape of the model positioned in the test section.

A submarine model with two different nose shapes is selected in the present work. A 1:152 scale model of the DARPA SUBOFF bare hull submarine [7] with a

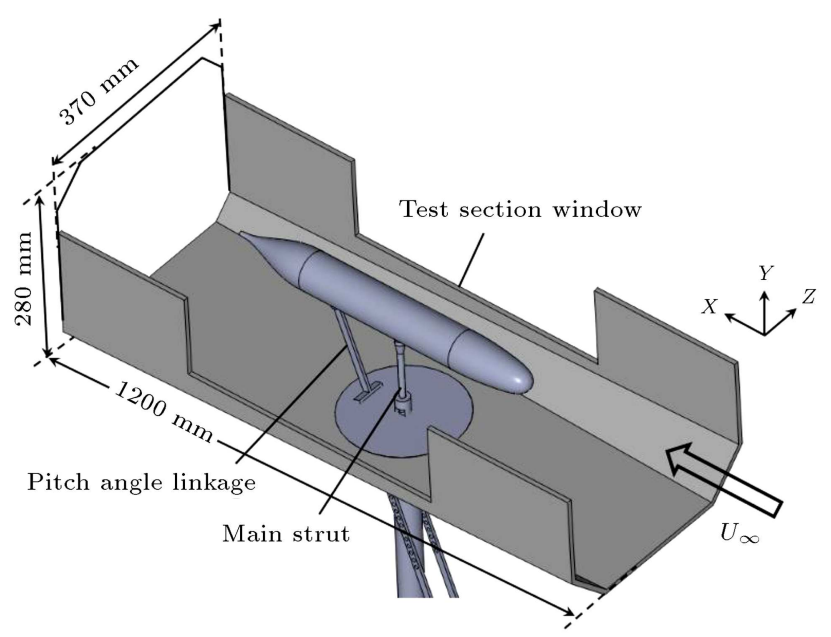

Figure 1. Schematic of the lower half part of the wind tunnel test section and the full shape of the model positioned in the test section.

length $(L)$ of $0.687 \mathrm{~m}$ and maximum diameter $(D)$ of $0.08 \mathrm{~m}$ is considered as the base model. The results of the pressure coefficient measured over this model are compared with the results of other works available in the literature for validation purposes. This model consists of three detachable parts: a nose (fore-body), a mid-body, and an after-body with the lengths of $L_{n} / L=0.23, L_{m} / L=0.51$, and $L_{a} / L=0.26$, respectively. To study the effect of nose shape on the flow characteristics around the nose, the SUBOFF nose is replaced with the DRDC submarine nose [18]. Two noses selected have the same length, $L_{n}$. The geometry of the SUBOFF model and DRDC submarine nose (the blunter nose) are shown in Figure 2. All parts of the models were machined from aluminium with an accuracy degree of $\pm 0.5 \mathrm{~mm}$.

The submarine model is mounted in the middle of the test section by an aluminium tube with a diameter of $10 \mathrm{~mm}$ working as the main strut, attached to the model at $X / L=0.5$ (Figure 1). The main strut exports the pressure tubes from the body to the pressure sensor box. The pitch angle $(\alpha)$ of the model is changed by a linkage that is attached to the model, as shown in Figure 1. The pressures and velocities are measured upstream of the support location and, therefore, the effect of support on these results is neglected.

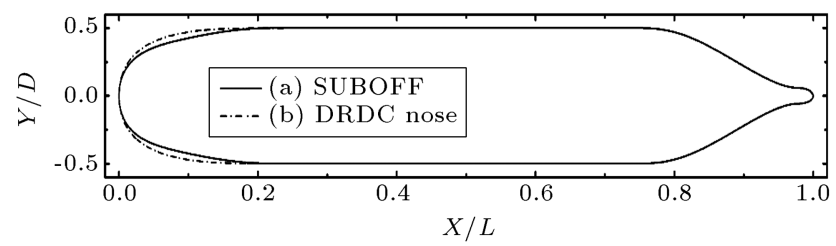

Figure 2. Schematic drawing of (a) SUBOFF model geometry as the base model and (b) the submarine model equipped with the DRDC nose. 
A trip strip is attached onto the nose surface to simulate the turbulent boundary layer flow around the model. A wire as the trip strip with a diameter of $0.6 \mathrm{~mm}$ was attached to the model nose circumferentially. For the SUBOFF model, the trip is placed at $X / L=0.05$ based on the work of Huang and Liu [8] and, for the DRDC model, the wire trip is placed at $X / L=0.03$ based on the recommendation of Watt et al. [18].

The combined blockage ratio due to the model and its support is below $5 \%$ at zero pitch angle. For higher pitch angles, the measured pressure coefficients and boundary layer velocities are corrected through Eqs. (1) and (2). In this equation, $C_{P v}, U_{v}$, and $q_{\infty v}$ are the measured pressure coefficient, velocity, and dynamic pressure; $C_{P}$ and $U$ are the corrected ones, respectively. Furthermore, the parameter $\varepsilon_{t}$ is the correction factor and $B R$ is the blockage ratio, presented in Eqs. (3) and (4) [22]. The parameter, $P(\mathrm{~Pa})$, is the local pressure on the surface; $P_{\infty}(\mathrm{Pa})$ and $U_{\infty}(\mathrm{m} / \mathrm{s})$ are the free-stream static pressure and velocity that are measured at the wind tunnel nozzle outlet by a pitotstatic tube, and $\rho\left(\mathrm{kg} / \mathrm{m}^{3}\right)$ is the airflow density.

$$
\begin{aligned}
& C_{p}=\frac{P-P_{\infty}}{\frac{1}{2} \rho U_{\infty}^{2}}=\frac{P-P_{\infty}}{q_{\infty v}\left(1+2 \varepsilon_{t}\right)}=\frac{C_{p v}}{\left(1+2 \varepsilon_{t}\right)}, \\
& U=U_{v} \sqrt{\left(1+2 \varepsilon_{t}\right)}, \\
& \varepsilon_{t}=\frac{1}{4} \times \text { BR (Blockage Ratio), }
\end{aligned}
$$

\section{BR (Blockage Ratio)}

$$
=\frac{\text { Model and support front area }}{\text { Wind tunnel test section area }} \text {. }
$$

\subsection{Experimental procedure and instruments}

The surface pressure distributions are measured by nine pressure taps positioned along the nose and five taps mounted along the mid-body. All pressure taps are connected to a multi-channel pressure box (pressure sensor Honeywell, DC005NDC4) in the measuring range of $\pm 1245 \mathrm{~Pa}$ and with an accuracy degree of $\pm 3 \mathrm{~Pa}$.

The longitudinal pressure distributions over the range of $0 \leq X / L \leq 0.23$ on the nose surface are recorded along the circumferential direction in the range of $0^{\circ}$ to $180^{\circ}$ with a $15^{\circ}$ increment by rotating the nose along its axis. The origin of circumferential direction $\left(\varphi=0^{\circ}\right)$ is in the symmetry plane on the windward side of the model, where the flow meets. The pressure data are collected for 105 locations on the one-half of nose surface $0^{\circ} \leq \varphi \leq 180^{\circ}$, as shown in Figure 3 (black spots). Moreover, Figure 3 shows the dimensions of the nose and the positions of the pressure data collections.

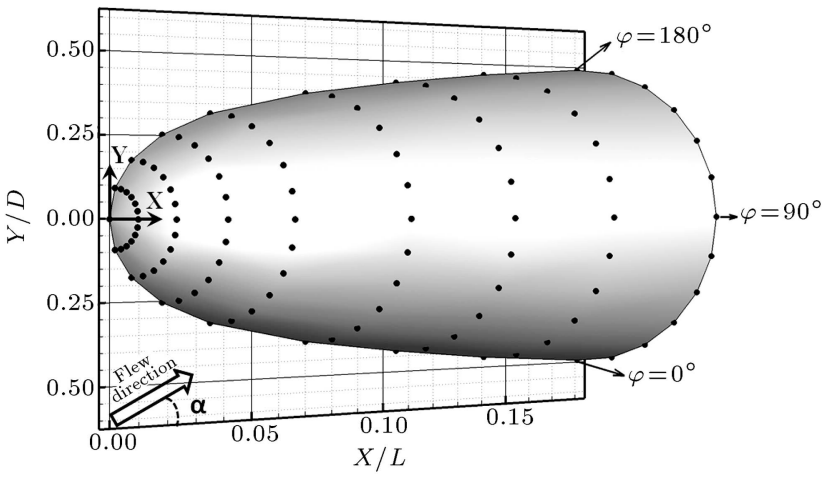

Figure 3. Nose dimensions and the locations of pressure data collections over the nose surface.

The pressure measurements are performed at three values of Reynolds numbers (based on the overall length of the model), i.e., $\operatorname{Re}=0.5 \times 10^{6}, 0.8 \times 10^{6}$, and $1 \times 10^{6}$ corresponding to three free stream velocities of $U_{\infty}=12,18$, and $24 \mathrm{~m} / \mathrm{s}$, respectively, and at various pitch angles $\alpha=0,5,10$, and $15^{\circ}$. The origin of the body coordinate system is located at the nose tip. The $X$-axis corresponds to the axis of symmetry of the model and is positive in the downstream direction. The direction of $X$ and $Y$ axes is also shown in Figure 3.

The boundary layer velocity profiles on the plane of symmetry on the leeward side $\left(\varphi=180^{\circ}\right)$ of the submarine nose were measured by applying a single probe hot wire anemometer. The single probe with a $0.5 \mathrm{~mm}$ tungsten wire is connected to a Constant Temperature Anemometer (CTA). The probe is mounted on a threedimensional traverse system with a movement accuracy degree of $0.01 \mathrm{~mm}$. For measuring the boundary layer accurately, the probe moves logarithmically on a line normal to the model surface and is controlled by computer software, and the data are acquired in 5 seconds in each location. The CTA has a temperature corrective probe that is placed in the flow and applies the effect of temperature variations during airflow measurement. The velocity measurement results are obtained for the model with both nose shapes at $\operatorname{Re}=1 \times 10^{6}$ and at three pitch angles of $\alpha=0,5$, and $10^{\circ}$ with trip strip on the nose. The measuring parameters and their corresponding uncertainties are listed in Table 1.

\section{Results and discussion}

In this study, the effects of the nose shape on the flow behavior over the nose surface of an axisymmetric submarine model are investigated and discussed at various pitch angles. The first part of the results focuses on the variations of the surface pressure coefficients with Reynolds number and pitch angles. Then, the effects of nose shape on the surface pressure distribution are investigated. In the second part, the effects 
Table 1. The relations and uncertainty values of the parameters.

\begin{tabular}{lcc}
\hline \multicolumn{1}{c}{ Parameter } & Relation & Relative uncertainty (\%) \\
\hline Free stream velocity $(\mathrm{m} / \mathrm{s})$ & $V_{\infty}=\sqrt{\frac{2 \Delta P}{\rho}}$ & $\frac{u_{V_{\infty}}}{V_{\infty}}=1.9$ \\
Reynolds number & $\operatorname{Re}=\frac{\rho V_{\infty} L}{\mu}$ & $\frac{u_{\mathrm{Re}}}{\mathrm{Re}}=2$ \\
Mean velocity $(\mathrm{m} / \mathrm{s})$ & $U$ & $\frac{u_{U}}{U}=3$ \\
Mean pressure $(\mathrm{Pa})$ & $P$ & $\frac{u_{P}}{P}=2$ \\
Pressure coefficient & $C_{P}=\frac{P-P_{S \infty}}{q_{\infty}}$ & $\frac{u_{C p}}{C_{P}}=3.4$ \\
\hline
\end{tabular}

Note: $\Delta P=$ Pitot static tube differential pressure $=P_{T \infty}-P_{S \infty}$.

of pressure gradient on the boundary layer velocity profiles are studied at various pitch angles on the plane of symmetry on the leeward side of the model $(\varphi=$ $180^{\circ}$ ). Moreover, the experimental results obtained for employing the SUBOFF model are compared with the available results in the literature.

\subsection{Surface pressure coefficient}

Pressure coefficient $\left(C_{P}\right)$, which is calculated by measuring surface pressure over the model, is defined by Eq. (5):

$$
C_{P}=\frac{P-P_{S \infty}}{\frac{1}{2} \rho U_{\infty}^{2}},
$$

where $P(\mathrm{~Pa})$ is the local surface pressure; $P_{S \infty}(\mathrm{Pa})$ and $U_{\infty}(\mathrm{m} / \mathrm{s})$ are the free-stream static pressure and velocity that are measured at the wind tunnel nozzle outlet by a pitot-static tube; $\rho\left(\mathrm{kg} / \mathrm{m}^{3}\right)$ is the airflow density.

Figure 4 shows the longitudinal distribution of the surface pressure coefficient on the SUBOFF model along the leeward plane $\left(\varphi=180^{\circ}\right)$ at $\operatorname{Re}=1 \times 10^{6}$ and at zero pitch angle. In addition, the SUBOFF model body curve is drawn in this figure. The present result is compared with the experimental result of Huang and Liu [8], reported at $\operatorname{Re}=12 \times 10^{6}$. It is seen that the present result is in good agreement with the result of Huang and Liu [8] in spite of the difference in the Reynolds number values. This is due to the presence

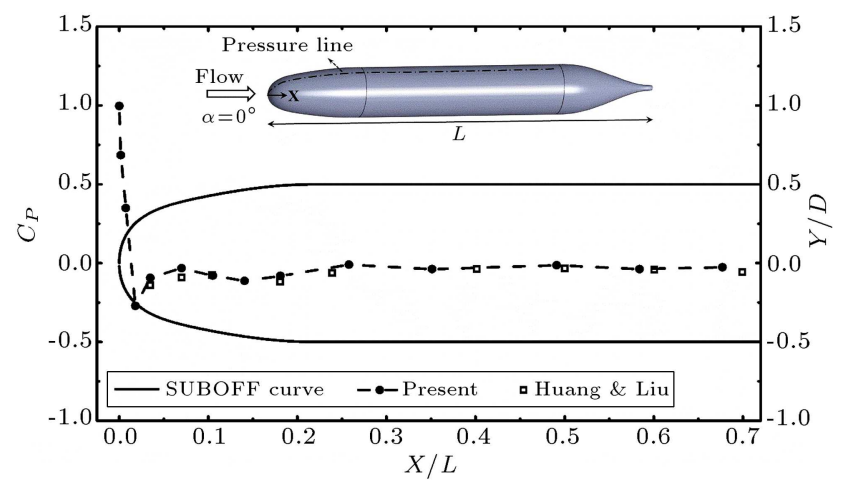

Figure 4. Pressure coefficient versus $X / L$ at zero pitch angle and at $R e=10^{6}$ for SUBOFF model along with the results of Huang and Liu [8].

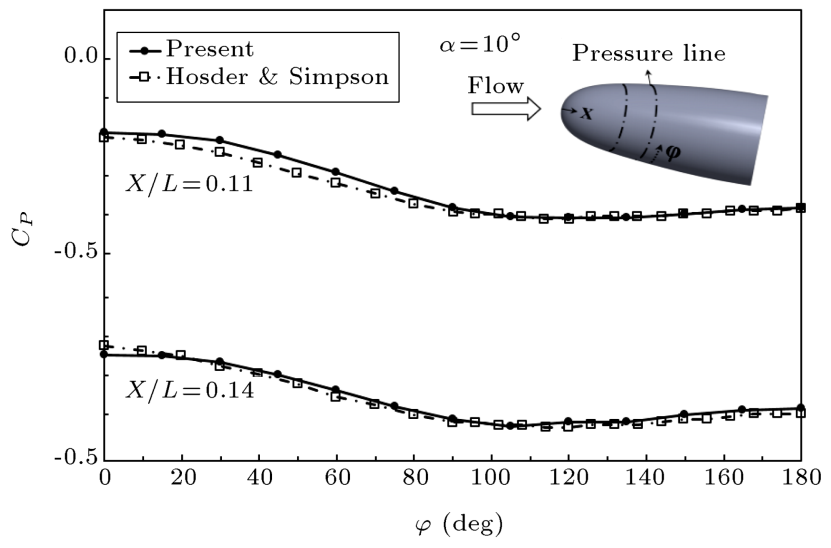

Figure 5. Pressure coefficient versus circumferential angle $(\varphi)$ at $\alpha=10^{\circ}$ and at $\operatorname{Re}=10^{6}$ for SUBOFF model along with the results of Hosder and Simpson [23].

of the fully turbulent boundary layer on the model surface. The pressure distribution near the nose tip $(0 \leq X / L \leq 0.035)$, where the minimum pressure takes place, was not measured by Huang and Liu [8].

Figure 5 illustrates the pressure coefficient versus circumferential angle in two longitudinal locations at $\alpha=10^{\circ}, \operatorname{Re}=10^{6}$ and for the SUBOFF model. The circumferential pressure distributions of the present work are compared with the same results of Hosder and Simpson [23] at $\operatorname{Re}=2.5 \times 10^{6}$. The results of Hosder and Simpson are measured at positions $X / L=0.11$ and $X / L=0.14$; however, the present surface pressure data are measured at positions $X / L=0.105$ and $X / L=0.14$. The observed slight discrepancy between the obtained results and those obtained by Hosder and Simpson in location $X / L=0.11$ results from the difference between the locations of the measurements.

\subsection{The effect of Reynolds number and pitch angle on the pressure results}

Detailed surface pressure measurements along the circumferential and longitudinal directions over the nose surface are achieved by rotating the nose around its axis. Figure 6 shows the contour of the pressure coefficient over the surface of the SUBOFF nose at $\operatorname{Re}=0.5 \times 10^{6}, 0.8 \times 10^{6}$, and $1 \times 10^{6}$ and at four pitch angles of $\alpha=0,5,10$, and $15^{\circ}$. The pressure data are obtained only on one-half of the nose surface 


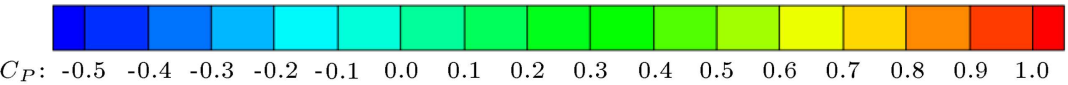

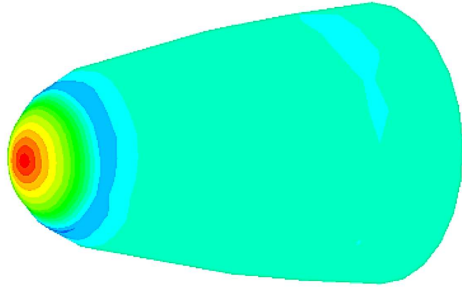

(a) $\operatorname{Re}=500000, \alpha=0^{\circ}$

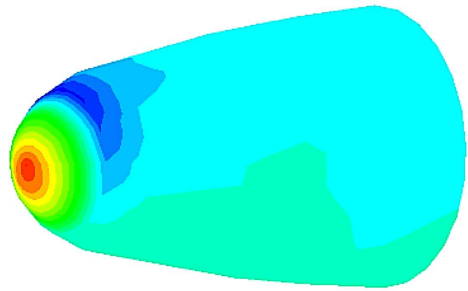

(d) $\operatorname{Re}=500000, \alpha=5^{\circ}$

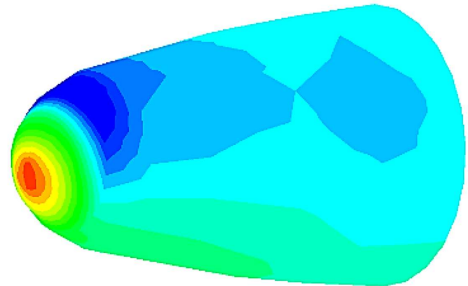

(g) $\operatorname{Re}=500000, \alpha=10^{\circ}$

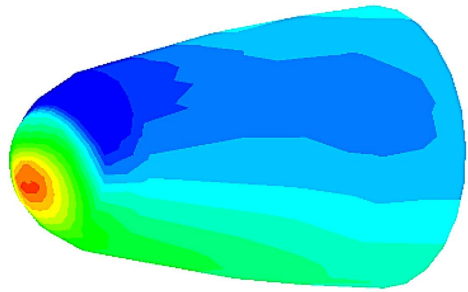

(j) $\operatorname{Re}=500000, \alpha=15^{\circ}$

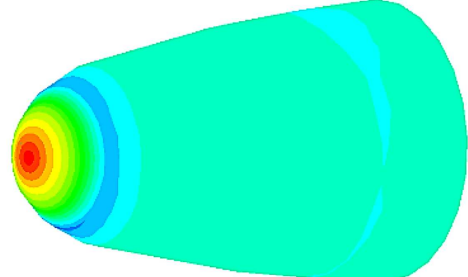

(b) $\operatorname{Re}=800000, \alpha=0^{\circ}$

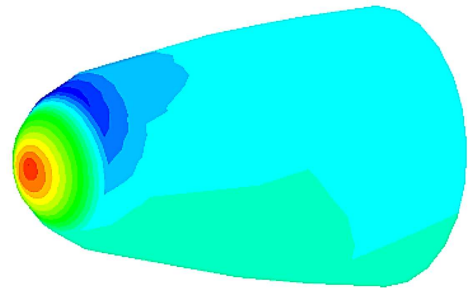

(e) $\operatorname{Re}=800000, \alpha=5^{\circ}$

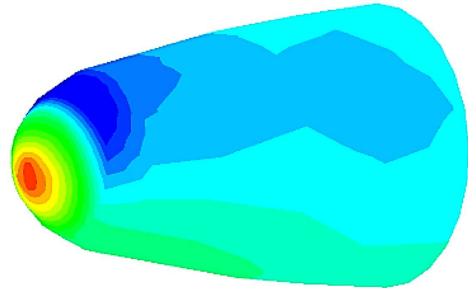

(h) $\operatorname{Re}=800000, \alpha=10^{\circ}$

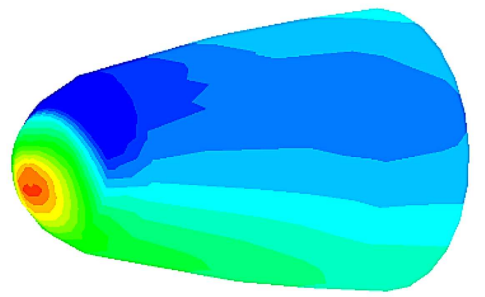

(k) $\operatorname{Re}=800000, \alpha=15^{\circ}$

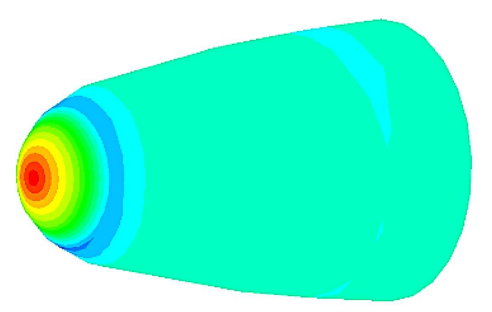

(c) $\operatorname{Re}=1000000, \alpha=0^{\circ}$

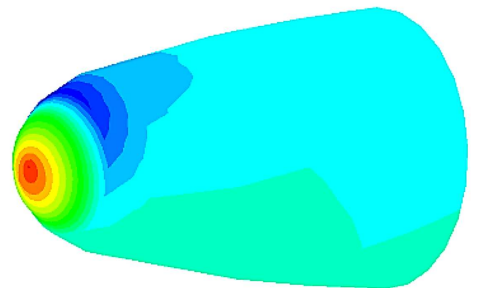

(f) $\operatorname{Re}=1000000, \alpha=5^{\circ}$

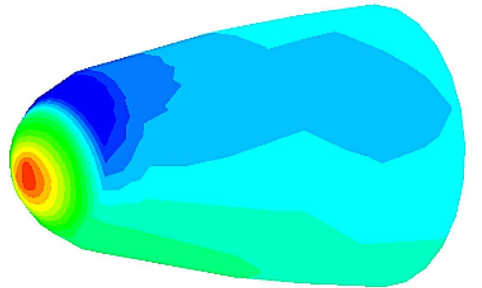

(i) $\operatorname{Re}=1000000, \alpha=10^{\circ}$

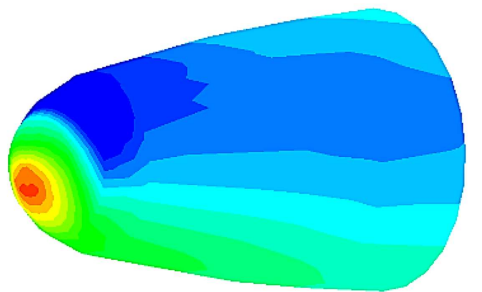

(1) $\operatorname{Re}=1000000, \alpha=15^{\circ}$

Figure 6. Contour of pressure coefficient over the surface of the SUBOFF nose at three Reynolds numbers of $0.5 \times 10^{6}$, $0.8 \times 10^{6}$, and $1.0 \times 10^{6}$ and at four pitch angles of $\alpha=0,5,10$, and $15^{\circ}$.

$0^{\circ} \leq \varphi \leq 180^{\circ}$ (see Figure 3 ); then, these data are considered for the other half part of the nose $180^{\circ} \leq$ $\varphi \leq 360^{\circ}$ due to the asymmetry of the nose and flow field. At zero pitch angle, the pressure field has the axial symmetry over the nose surface (as shown in Figure 6(a)-(c)). The longitudinal pressure gradient is dominant in the flow around the nose. The pressure coefficient has the maximum value $\left(C_{P}=1.0\right)$ at the incident point, where the flow stagnates $(X / L=0)$ and decreases along the nose until reaching a minimum value $\left(C_{P}=-0.26\right)$. The pressure distribution has a favorable gradient in this portion. Then, the pressure increases (adverse pressure gradient) and remains close to zero towards the nose end.

The effect of Reynolds number on the nose surface pressure at zero pitch angle is depicted in Figure 6(a)(c). No significant variation in the surface pressure coefficient is seen as the Reynolds number varies. As the pitch angle increases, the circumferential pressure gradient appears on the nose surface between windward and leeward sides, although the longitudinal pressure gradient is also present. On the leeward symmetry plane $\left(\varphi=180^{\circ}\right)$, the longitudinal pressure gradient becomes stronger and the minimum pressure coefficient decreases (increases in absolute value) when the pitch angle increases. The minimum of $C_{P}=-0.26$ at $\alpha=0^{\circ}$ is changed to $C_{P}=-1.0$ at $\alpha=15^{\circ}$ on the leeward side of the model at the same longitudinal position. On the windward symmetry plane $(\varphi=0)$, pressure takes its maximum value close to the tip and, then, increases due to the flow acceleration towards the nose end.

Figure 7 shows the contour of pressure coefficient over the surface of the SUBOFF and DRDC noses at 


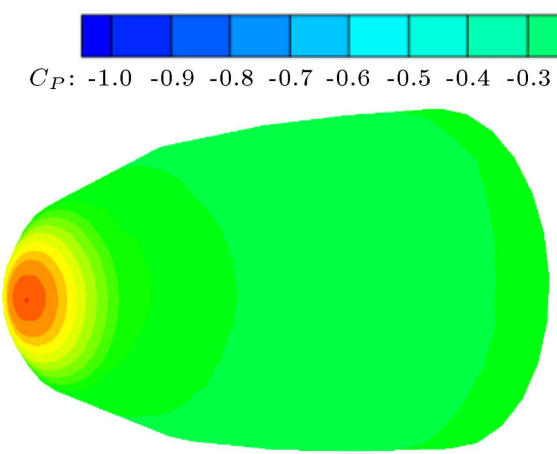

(a) $\operatorname{Re}=1000000, \alpha=0^{\circ}$, DRDC STR

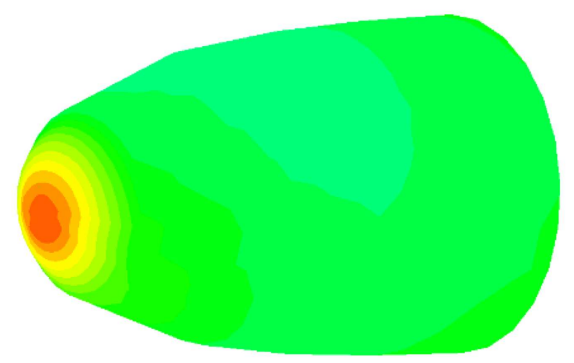

(c) $\operatorname{Re}=1000000, \alpha=5^{\circ}, \mathrm{DRDC} \mathrm{STR}$

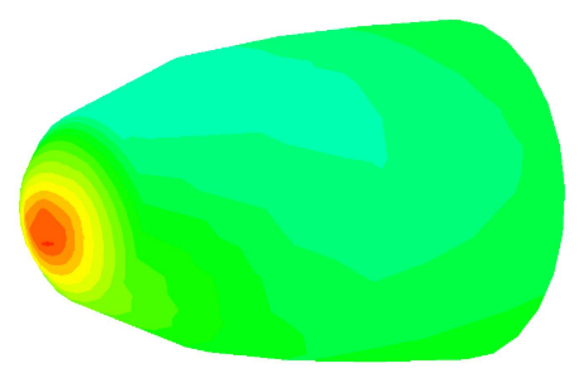

(e) $\operatorname{Re}=1000000, \alpha=10^{\circ}, \mathrm{DRDC} \mathrm{STR}$

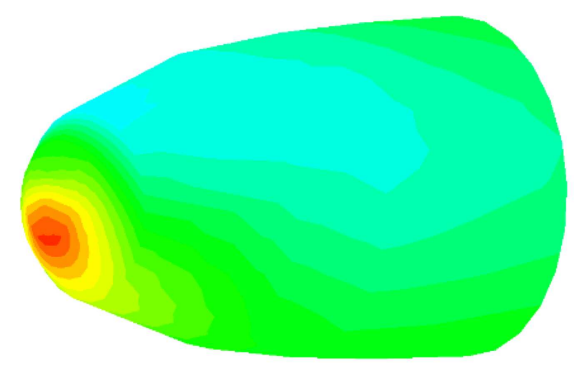

(g) $\operatorname{Re}=1000000, \alpha=15^{\circ}, \mathrm{DRDC} \mathrm{STR}$

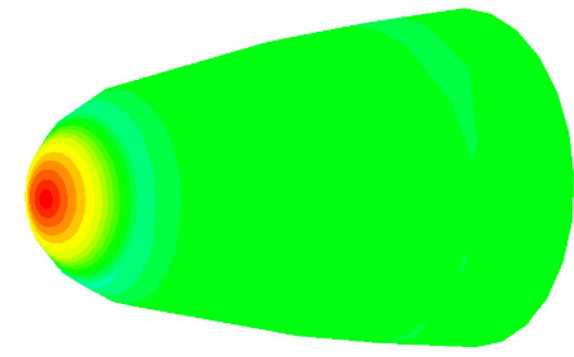

(b) $\operatorname{Re}=1000000, \alpha=0^{\circ}$, SUBOFF

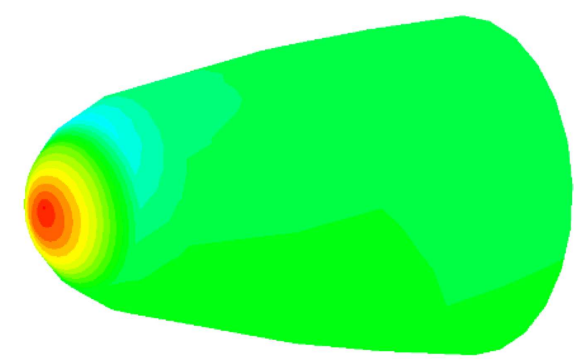

(d) $\operatorname{Re}=1000000, \alpha=5^{\circ}$, SUBOFF

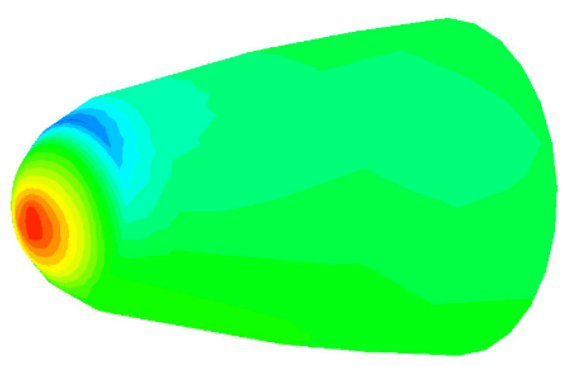

(f) $\operatorname{Re}=1000000, \alpha=10^{\circ}, \mathrm{SUBOFF}$

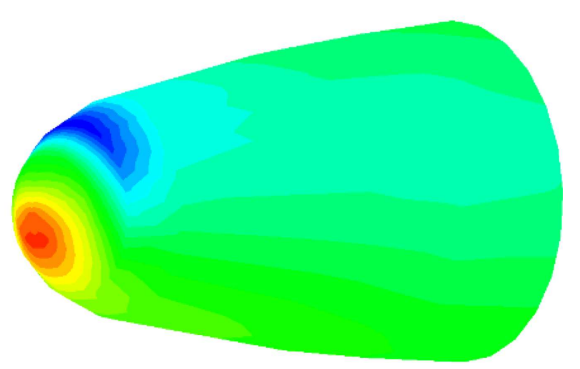

(h) $\operatorname{Re}=1000000, \alpha=15^{\circ}$, SUBOFF

Figure 7. Contour of pressure coefficient over the surface of the SUBOFF and DRDC noses at Reynolds number $1.0 \times 10^{6}$ and at four pitch angles of $\alpha=0,5,10$, and $15^{\circ}$.

$\operatorname{Re}=1.0 \times 10^{6}$ and at four pitch angles of $\alpha=0,5,10$, and $15^{\circ}$. For both noses, the pressure coefficient has the maximum value at the incident point and decreases along the nose until reaching the minimum value. The place and the amount of the minimum value of pressure coefficient strongly depend on the nose shape. The adverse longitudinal pressure gradient is observed for both noses after minimum pressure location; however, the pressure recovery on the SUBOFF nose is more pronounced after its minimum value and remains close to zero afterward. The pressure coefficient results at $\alpha=10^{\circ}$ are presented in Figure 7(e)-(f). It is seen that the greater portion of the DRDC nose is subjected to a positive pressure gradient at high pitch angles.

\subsection{Boundary layer behavior on the symmetry plane at the pitch angle}

In this section, the characteristics of velocity profiles of the boundary layer on the symmetry plane of the submarine nose $\left(\varphi=180^{\circ}\right)$ are studied at $\operatorname{Re}=$ 


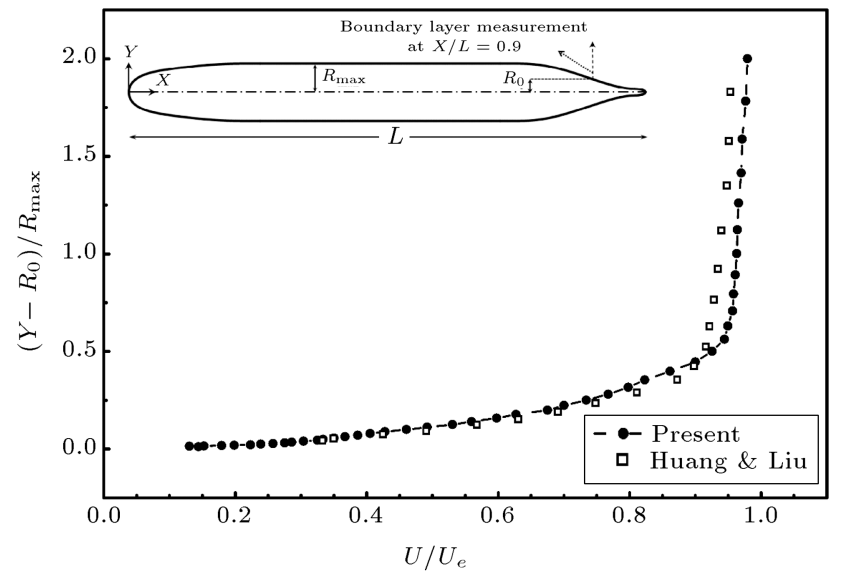

Figure 8. Boundary layer profiles in location $X / L=0.9$ at zero pitch angle and $R e=10^{6}$ for SUBOFF model in comparison with the study of Huang and Liu [8].

$10^{6}$ and at three pitch angles of $\alpha=0,5$, and $10^{\circ}$. The boundary layer profiles are measured in five longitudinal locations of $X / L=0.05,0.09,0.14$, 0.19 , and 0.23 along the nose on the leeward plane of symmetry $\left(\varphi=180^{\circ}\right)$ by a hotwire anemometer.

Moreover, the boundary layer profile in location $X / L=0.9$ is also measured and compared with the results of Huang and Liu [8]. Figure 8 shows the boundary layer velocity profile in location $X / L=0.9$ on the leeward symmetry plane $\left(\varphi=180^{\circ}\right)$ for the SUBOFF model at zero pitch angle and at $\mathrm{Re}=10^{6}$. The result obtained by Huang and Liu [8] is also shown in this figure. The non-dimensional boundary layer velocity profile $\left(U / U_{e}\right)$ is depicted versus the nondimensional distance from the surface $\left(Y-R_{0} / R_{\max }\right)$. The comparison of the present results and the study of Huang and Liu [8] experiments shows that the trend of the velocity profile of the boundary layer is very well predicted by the present work; however, some differences between the results are seen in the range of $0.5 \leq\left(Y-R_{0} / R_{\max }\right)$. In the present work, $U_{e}$ is the velocity at the edge of the boundary layer at $X / L=0.9$, while Huang and Liu [8] used the velocity of the flow outside the boundary layer at $X / L=0.75$ as the scaling velocity whose value remains unknown. This might be the reason for the discrepancy between both results, as presented in Figure 8.

\subsection{The effect of pitch angle and pressure gradient on the boundary layer profiles}

The boundary layer thickness on the nose surface is much less than the model diameter; therefore, the effect of span-wise model curvature can be neglected [4]. The boundary layer on the plane of symmetry is intermediate in complexity between the axisymmetric boundary layer and the fully three-dimensional boundary layer [6]. The flows on the plane of symmetry do not experience the cross flow, but become subject to the

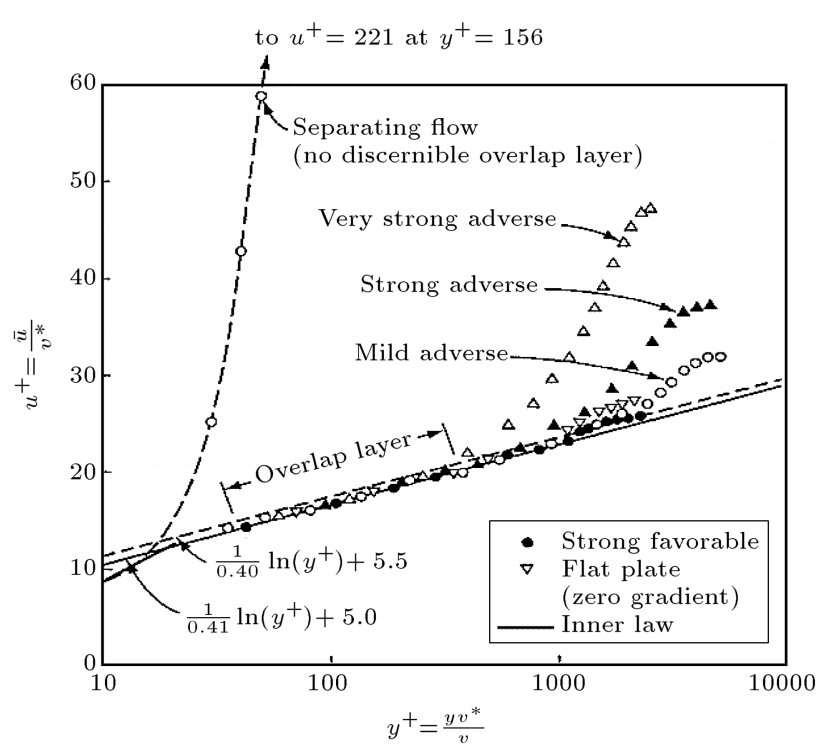

Figure 9. The effects of pressure gradients on the non-dimensional turbulent boundary layer velocity profiles [24].

longitudinal pressure gradient. The longitudinal pressure gradient affects the shape of the two-dimensional boundary layer profiles, and the boundary layer might undergo longitudinal separation. The effects of various pressure gradients on the velocity profiles of the nondimensional turbulent boundary layer are shown in Figure 9 [24]. White and Corfield [24] noted that the boundary layer velocity profiles (as seen in Figure 9) with different strength rates of pressure gradients collapsed into a single logarithmic law in the region of $35<y^{+}<350$, with the exception of the separating flow boundary layer. When the curves turn upward in the outer layer $y^{+} \geq 350$, the effect of pressure gradient on the boundary layer profiles is more pronounced and leads to their deviation from the logarithmic law.

In the present work, most of the boundary layer velocity profiles are logarithmically drawn at a nondimensional distance from the surface, $Y^{+}$, and nondimensional velocity, $U^{+}$, defined in $\mathrm{Eq}$. (6):

$$
Y^{+}=\frac{\left(Y-R_{0}\right) \rho u^{*}}{\mu}, \quad U^{+}=\frac{U}{u^{*}} .
$$

In addition, the profiles of the viscous sub-layer (Eq. (7)), log layer (Eq. (8)), and Spalding's single formula for law of the wall [25], as presented by Eq. (9), are shown in each location. In Eq. (9), $K$ and $C$ are the constant parameters of Spalding's equation [25]. Initially, the value of the friction velocity, $u^{*}$, is not known in Eq. (6). Hence, its value changes over an appropriate range until an optimum value is obtained, which best matches the inner Spalding [25] boundary layer profile (Eq. (9) with $K=0.4$ and $C=5.0$ ) with the non-dimensionalized outer layer measured data [26]. 


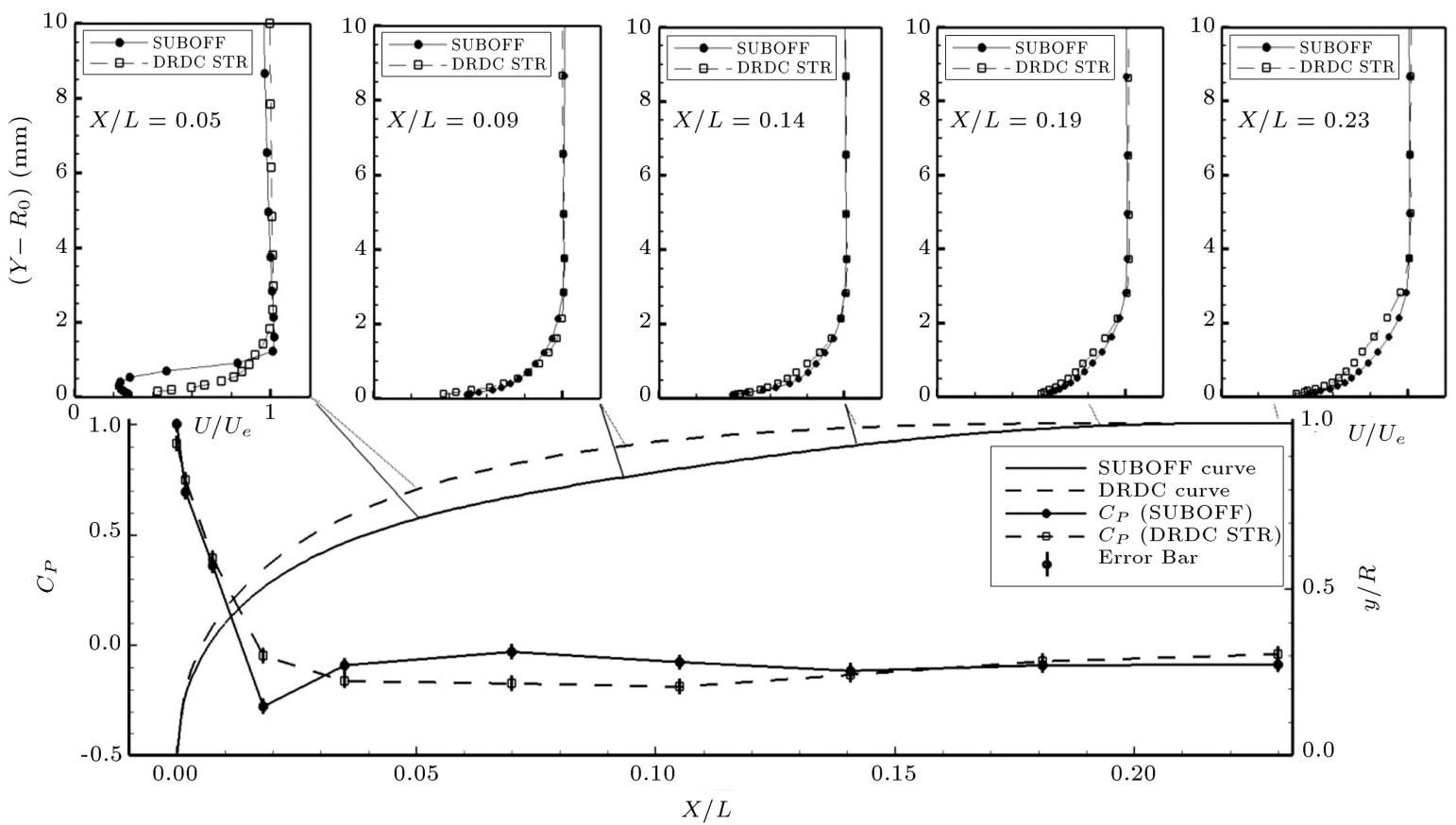

Figure 10. Pressure coefficient distribution and boundary layer profiles at five positions along the nose surface over DRDC and SUBOFF models at $\alpha=0^{\circ}$ with a pressure error bar.

$$
\begin{aligned}
& U^{+}=Y^{+}: \quad \text { Viscous sublayer, } \\
& U^{+}=\frac{1}{0.4} \ln \left(Y^{+}\right)+5: \quad \text { The log layer, } \\
& y^{+}=U^{+}+\frac{1}{e^{K C}}\left\{e^{K U^{+}}-\left[1+K U^{+}+\frac{\left(K U^{+}\right)^{2}}{2 !}\right.\right. \\
& \left.\left.+\frac{\left(K U^{+}\right)^{3}}{3 !}\right]\right\} .
\end{aligned}
$$

Figure 10 shows the boundary layer velocity profiles in five locations of $X / L=0.05,0.09,0.14,0.19$, and 0.23 along the nose surface of DRDC and SUBOFF models at $\alpha=0^{\circ}$. The streamwise component of the velocity $(U)$ is non-dimensionalized with the velocity at the boundary layer edge $\left(U_{e}\right)$. Moreover, the nose curvature and longitudinal pressure distribution of two nose shapes are shown in Figure 10. As may be seen, the SUBOFF boundary layer velocity profiles at all positions have negative curvature due to the negative pressure gradient along the nose, except for the profile at position $X / L=0.05$. The sharp and deflective SUBOFF profile in location $X / L=0.05$ results from the presence of the trip strip at this position. The minimum of the longitudinal pressure coefficient for the SUBOFF nose occurs in the range of $0.01 \leq X / L \leq$ 0.03 , while the pressure coefficient increases suddenly and remains close to zero afterward and in the location range of $0.03<X / L \leq 0.23$. For the DRDC nose, the pressure coefficient after the minimum location
$(0.07 \leq X / L \leq 0.14)$ increases gradually along the nose $(0.14<X / L<0.23)$.

Figure 11 shows the non-dimensional boundary layer velocity profiles measured in five longitudinal locations of $X / L=0.05,0.09,0.14,0.19$, and 0.23 along the nose surface for two DRDC and SUBOFF models at $\alpha=0^{\circ}$. In addition, the profiles of the viscous sub-layer, log layer, and Spalding [25] are shown in each location. The effect of the longitudinal pressure gradient is seen in Figure 11. The non-dimensional boundary layer profile deviates from the log layer profile (or Spalding profile) as $X / L$ increases. However,

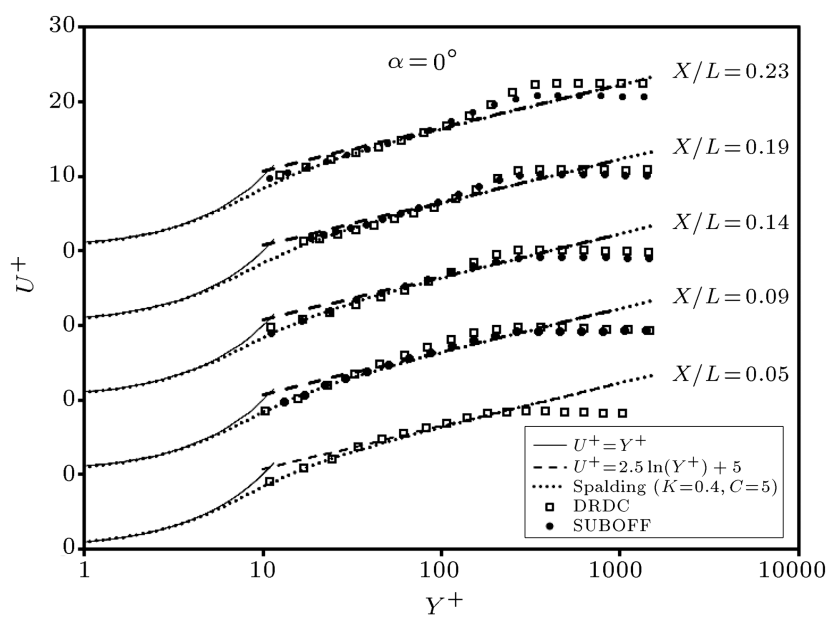

Figure 11. Non-dimensional boundary layer profiles in five locations along the nose surface over for DRDC and SUBOFF models at $\alpha=0^{\circ}$. 


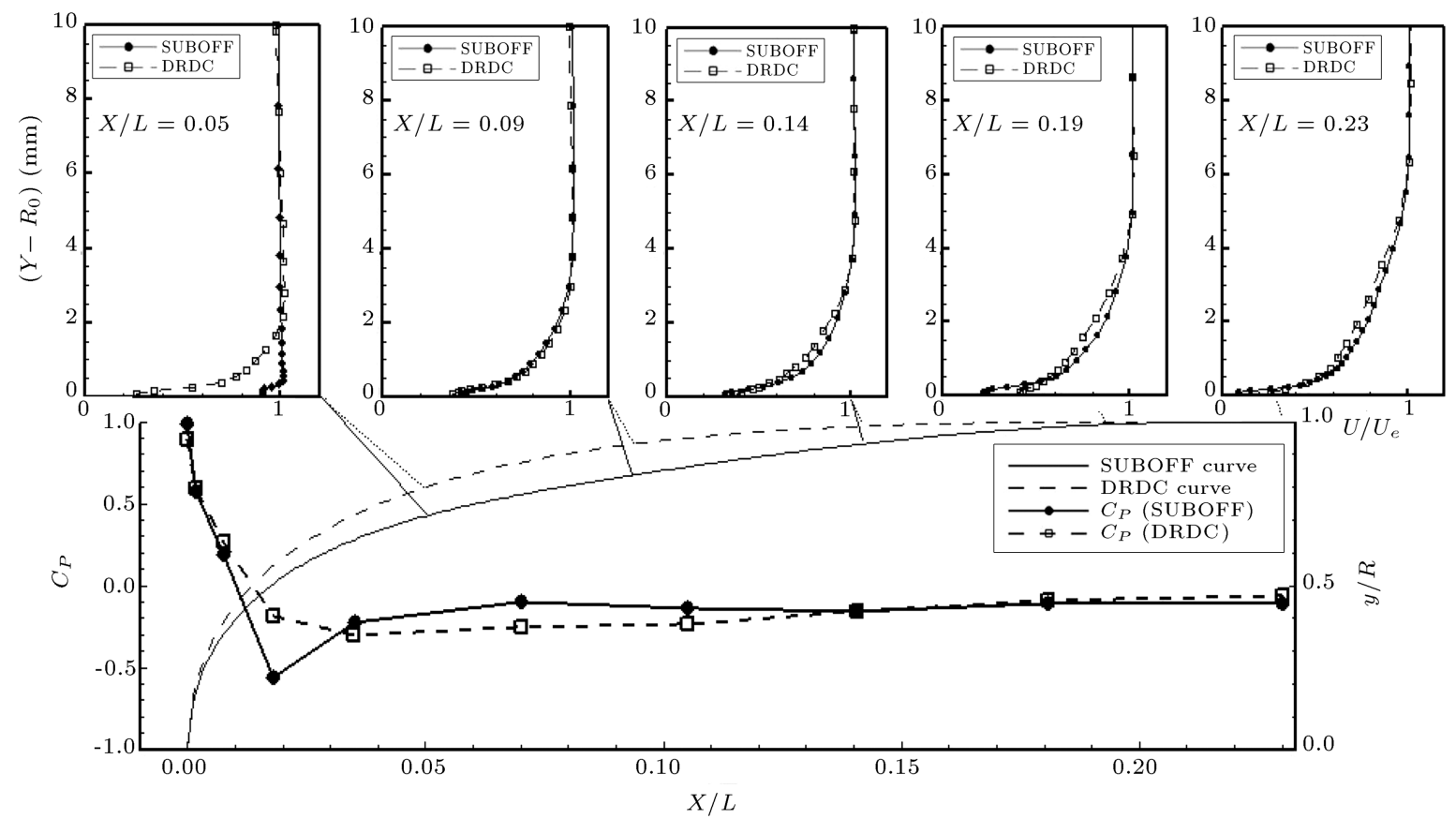

Figure 12. Pressure coefficient distribution and boundary layer profiles at five positions along the nose surface over DRDC and SUBOFF models at $\alpha=5^{\circ}$.

for the SUBOFF nose, this deviation is less pronounced than the DRDC nose one.

Figures 12 and 13 show the boundary layer velocity profiles along the nose surface of two models at $\alpha=$ $5^{\circ}$. The surface pressure coefficient distribution is also shown in Figure 12. The surface pressure coefficient distributions along the two nose shapes showed that the pressure gradient became stronger as pitch angle increased. The boundary layer velocity profiles for the DRDC nose shape in the longitudinal locations of $0.1 \leq$ $X / L \leq 0.23$ were more affected by the adverse pressure gradient at a pitch angle of $\alpha=5^{\circ}$ than at $\alpha=0^{\circ}$.

Figures 14 and 15 show the boundary layer ve-

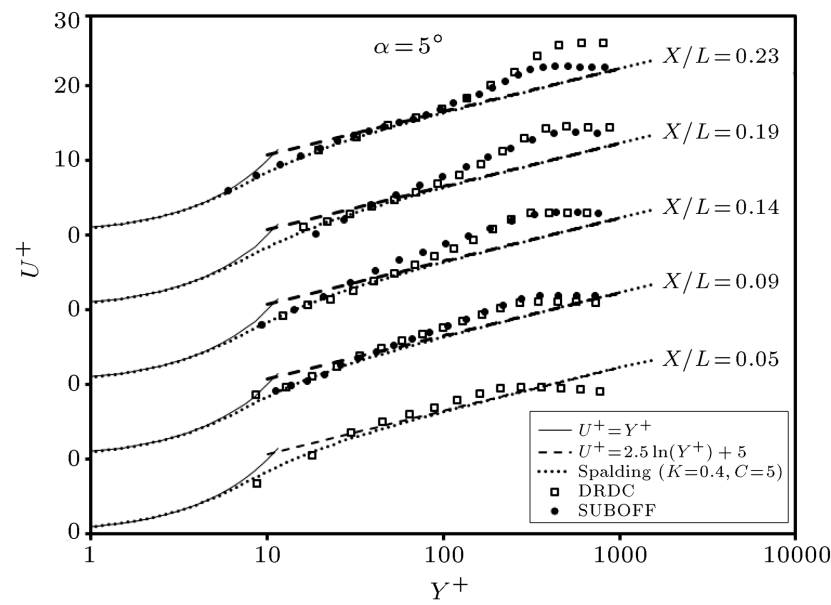

Figure 13. Non-dimensional boundary layer profiles at five positions along the nose surfaces of DRDC and SUBOFF models at $\alpha=5^{\circ}$. locity profiles along the nose surface of two models at $\alpha=10^{\circ}$. A close look into the boundary layer velocity profiles on the surface of DRDC and SUBOFF nose shapes with different pressure distributions shows that the presence of the mild adverse pressure gradient in greater portion of the DRDC nose has greater effect than the sudden loss of pressure in a small portion of the SUBOFF nose. The presence of adverse pressure gradient in a greater portion of the DRDC nose indicates that the separation on the standard nose is more probable than that on the SUBOFF nose at high pitch angles. The flow visualization conducted by Saeidinezhad et al. [11] revealed the same evidence on the nose flow separation. The adverse longitudinal pressure gradient is greater for the DRDC nose (blunter nose) and, therefore, the nose separation for the DRDC nose occurs at a smaller angle of incidence than the SUBOFF nose [11].

\section{Conclusions}

In the present study, the flow behavior over two different nose shapes of a submarine model at different pitch angle manoeuvres was investigated. The surface pressure distributions and boundary layer profiles over the SUBOFF and DRDC noses were measured in a wind tunnel. The study presented the effect of Reynolds numbers, i.e., $\operatorname{Re}=0.5 \times 10^{6}, 0.8 \times 10^{6}$, and $10^{6}$, and pitch angles, i.e., $\alpha=0,5,10$, and $15^{\circ}$, on the surface pressure contours for two nose shapes. The boundary layer velocity profiles along the two nose 


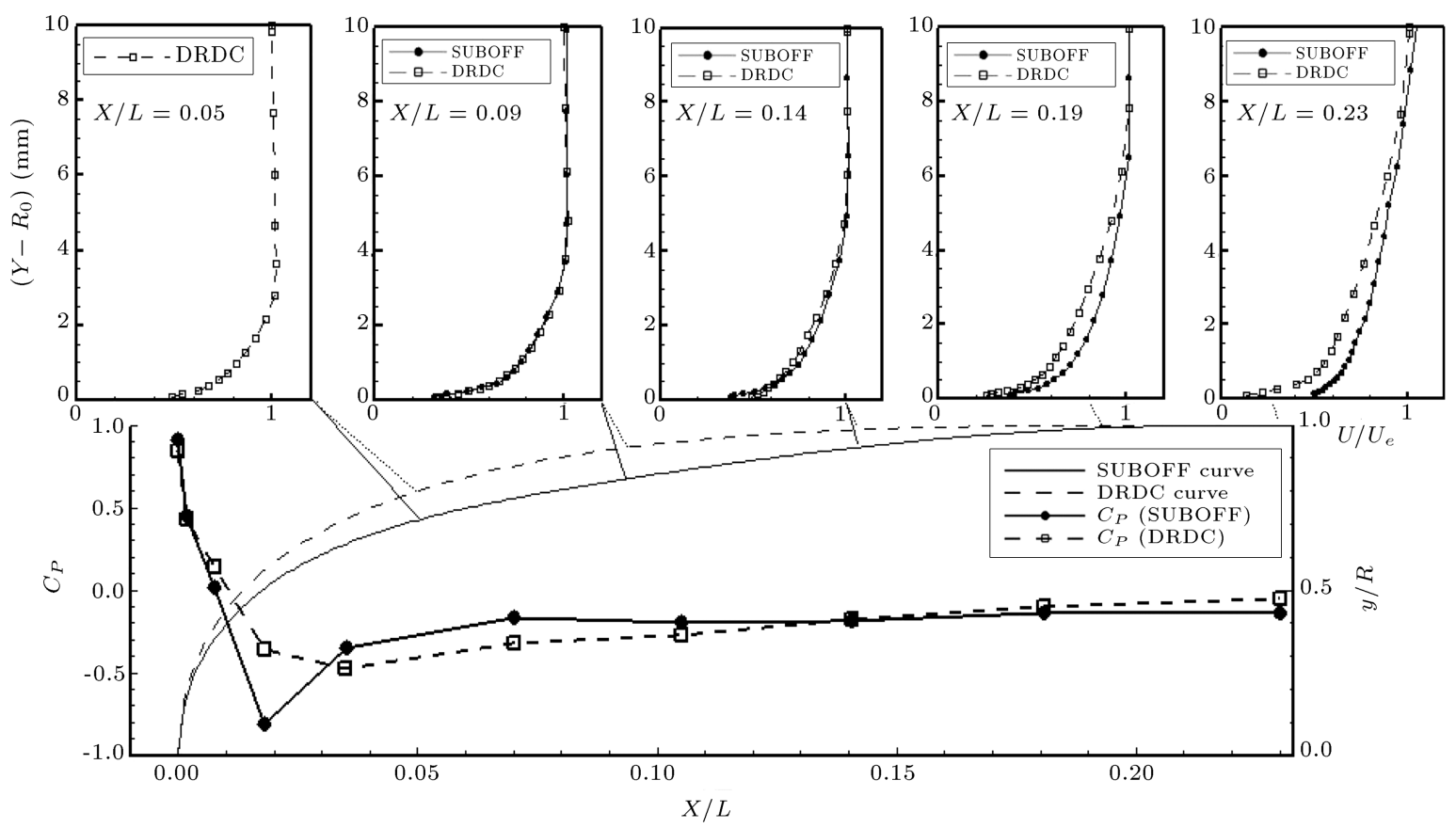

Figure 14. Pressure coefficient distribution and boundary layer profiles at five positions along the nose surface of DRDC and SUBOFF models at $\alpha=10^{\circ}$.

shapes at three pitch angles of $\alpha=0,5$, and $10^{\circ}$ and at $\operatorname{Re}=10^{6}$ were also studied. The major conclusions of this study may be summarized as follows:

1. The comparison of measured longitudinal and circumferential pressure coefficients and the referenced experimental results showed good agreement between them and revealed the fully turbulent boundary layer profiles over the body length;

2. Reynolds number did not have a significant effect on the nose surface pressure distribution at all pitch angles considered;

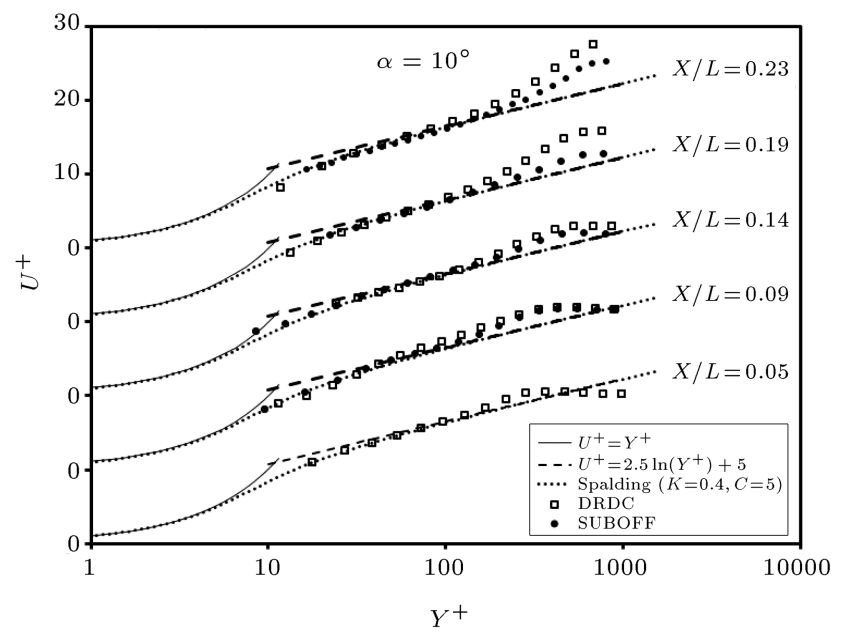

Figure 15. Non-dimensional boundary layer profiles at five positions along the nose surface of DRDC and SUBOFF models at $\alpha=10^{\circ}$.
3. The comparison of the surface pressure coefficient distributions on the surfaces of SUBOFF and DRDC noses revealed that the minimum pressure coefficient for two nose shapes was observed in different locations. Subsequently, the pressure on the SUBOFF nose increased suddenly and remained close to zero. However, for the DRDC nose, the major portion of the nose surface was subjected to a positive pressure gradient;

4. The non-dimensional boundary layer profile was seen to be affected by the longitudinal pressure gradients. For the SUBOFF nose, the non-dimensional boundary layer velocity profiles at all longitudinal positions did not undergo much deviation from the log layer profile along the nose. However, the nondimensional boundary layer velocity profiles for the DRDC nose in locations of $0.1 \leq X / L \leq 0.23$ were highly affected by the presence of adverse pressure gradient and, thus, deviated from the log layer profile (or Spalding profile);

5. The presence of the adverse pressure gradient in the greater portion of the DRDC nose indicated that the separation on the DRDC nose was more likely than that on the SUBOFF nose at higher pitch angles. This was also supported by the flow visualization results of Saeidinezhad et al. [11], which confirmed the behavior of the boundary layer velocity profiles presented here. 


\section{Nomenclature}

C Constant parameter of Spalding's equation

$C_{P} \quad$ Pressure coefficient

$C_{P v} \quad$ Uncorrected pressure coefficient

$D \quad$ Maximum diameter of the model (m)

$K \quad$ Constant parameter of Spalding's equation

L Model length (m)

$L_{a} \quad$ After-body length (m)

$L_{m} \quad$ Mid-body length (m)

$L_{n} \quad$ Nose length $(\mathrm{m})$

$P \quad$ Pressure $(\mathrm{Pa})$

$P_{\infty} \quad$ Free stream pressure $(\mathrm{Pa})$

$P_{S \infty} \quad$ Free stream static pressure $(\mathrm{Pa})$

$P_{T \infty} \quad$ Free stream total pressure $(\mathrm{Pa})$

$q_{\infty} \quad$ Free stream dynamic pressure $(\mathrm{Pa})$

$q_{\infty v} \quad$ Uncorrected free stream dynamic pressure $(\mathrm{Pa})$

$R_{0} \quad$ Local radius of the model (m)

$R_{\max } \quad$ Maximum radius of the model (m)

Re Model length Reynolds number

$U \quad$ Streamwise velocity $(\mathrm{m} / \mathrm{s})$

$U_{v} \quad$ Uncorrected streamwise velocity $(\mathrm{m} / \mathrm{s})$

$u^{*} \quad$ Friction velocity $(\mathrm{m} / \mathrm{s})$

$U_{\infty} \quad$ Free stream velocity $(\mathrm{m} / \mathrm{s})$

$U^{+} \quad$ Non-dimensional velocity

$X \quad$ Longitudinal axis along the model $(\mathrm{m})$

$Y \quad$ Vertical axis $(\mathrm{m})$

$Y^{+} \quad$ Non-dimensional distance from the surface

$\alpha \quad$ Pitch angle (deg)

$\mu \quad$ Dynamic viscosity

$\rho \quad$ Fluid density $\left(\mathrm{kg} / \mathrm{m}^{3}\right)$

$\varphi \quad$ Circumferential direction (deg)

$\varepsilon_{t} \quad$ Correction factor of the blockage ratio

\section{References}

1. Pantelatos, D.K. and Mathioulakis, D.S. "Experimental flow study over a blunt-nosed axisymmetric body at incidence", Journal of Fluids and Structures, 19, pp. 1103-1115 (2004).

2. Paster, D., Importance of Hydrodynamic Considerations for Underwater Vehicle Design, 86th OCEANS, Washington, DC, USA (1986).
3. Saeidinezhad, A., Dehghan, A., and Manshadi, M.D. "Experimental investigation of hydrodynamic characteristics of a submersible vehicle model with a nonaxisymmetric nose in pitch maneuver", Ocean Engineering, 100, pp. 26-34 (2015).

4. Patel, V., Nakayama, A., and Damian, R. "Measurements in the thick axisymmetric turbulent boundary layer near the tail of a body of revolution", Journal of Fluid Mechanics, 63, pp. 345-367 (1974).

5. Ramaprian, B., Patel, V., and Choi, D. "Mean-flow measurements in the three-dimensional boundary layer over a body of revolution at incidence", Journal of Fluid Mechanics, 103, pp. 479-504 (1981).

6. Patel, V. and Baek, J. "Boundary layers in planes of symmetry. I-Experiments in turbulent flow", AIA A Journal, 25, pp. 550-559 (1987).

7. Groves, N.C., Huang, T.T., and Chang, M.S. "Geometric characteristics of DARPA suboff models: (DTRC Model Nos. 5470 and 5471)", Report David Taylor Research Center (1989).

8. Huang, T. and Liu, H. "Measurements of flows over an axisymmetric body with various appendages in a wind tunnel: the DARPA SUBOFF experimental program", 19th Symposium on Naval Hydrodynamics, Seoul, Korea (1994).

9. Javadi, M., Manshadi, M.D., Kheradmand, S., and Moonesun, M. "Experimental investigation of the effect of bow profiles on resistance of an underwater vehicle in free surface motion", Journal of Marine Science and Application, 14, pp. 53-60 (2015).

10. Abedi, S., Dehghan, A.A., Saeidinezhad, A., and Manshadi, M.D. "Effects of bulbous bow on cross-flow vortex structures around a streamlined submersible body at intermediate pitch maneuver: A numerical investigation", Journal of Marine Science and Application, 15, pp. 8-15 (2016).

11. Saeidinezhad, A., Dehghan, A.A., and Dehghan Manshadi, M. "Nose shape effect on the visualized flow field around an axisymmetric body of revolution at incidence", Journal of Visualization, 18, pp. 1-11 (2014).

12. Roddy, R.F. "Investigation of the stability and control characteristics of several configurations of the DARPA SUBOFF model (DTRC Model 5470) from captivemodel experiments", Report David Taylor Research Center (1998).

13. Van Randwijck, E.F. and Feldman, J.P. "Results of experiments with a segmented model to investigate the distribution of the hydrodynamic forces and moments on a streamlined body of revolution at an angle of attack or with a pitching angular velocity", DTIC report document (2000).

14. Zhang, S., Li, H., Pang, Y., Chen, Q., and Yan, P. "Experimental investigation on roll stability of blunt-nose submarine in buoyantly rising maneuvers", Applied Ocean Research, 81, pp. 34-46 (2018). 
15. Akbarzadeh, P., Molana, P., and Badri, M.A. "Determining resistance coefficient for series 60 vessels using numerical and experimental modelling", Ships and Offshore Structures, pp. 1-6 (2015).

16. Ram, B.R.R., Surendran, S., and Lee, S. "Computer and experimental simulations on the fin effect on ship resistance", Ships and Offshore Structures, 10, pp. 122-131 (2015).

17. Park, J.Y., Kim, N., and Shin, Y.K. "Experimental study on hydrodynamic coefficients for high-incidenceangle maneuver of a submarine", International Journal of Naval Architecture and Ocean Engineering, 9, pp. 100-113 (2017).

18. Watt, G., Nguyen, V., Cooper, K., and Tanguay, B. "Wind tunnel investigations of submarine hydrodynamics. The development of the DREA static test rig and some results", Can. Aeronaut. Space J./J. Aeronaut. Spat. Can., 39, pp. 119-126 (1993).

19. Altosole, M. and Francescutto, A. "Influence of sea state models on calculated naval vessel stress spectra", Report Defence Research and Development Canada (2015).

20. Hajizadeh, S., Seif, M.S., and Mehdigholi, H. "Determination of ship maneuvering hydrodynamic coefficients using system identification technique based on free-running model test", Scientia Iranica, 23, pp. 2154-2165 (2016).

21. Javanmardi, M., Binns, J.R., Thomas, G.A., and Renilson, M.R. "An investigation into the effect of pressure source parameters and water depth on the wake wash wave generated by moving pressure source", Scientia Iranica, 25, pp. 2162-2174 (2018).

22. Barlow, J.B., Rae, W.H., and Pope, A., Low-speed wind Tunnel Testing, In John Wiley and Sons, 3th Ed. (1999).

23. Hosder, S. and Simpson, R.L. "Unsteady skin-friction measurements on a maneuvering DARPA2 SUBOFF model", Virginia Polytechnic, Report No. VPI-AOE272 (2001).

24. White, F.M. and Corfield, I., Viscous Fluid Flow, 3, McGraw-Hill New York (1991).
25. Spalding, D. "A single formula for the, law of the wall", Journal of Applied Mechanics, 28, pp. 455-458 (1961).

26. DeMoss, J.A. "Skin friction and cross-flow separation on an ellipsoidal body during constant yaw turns and a pitch-up maneuver with roll oscillation", $\mathrm{PhD}$ Thesis, Virginia Tech. (2010).

\section{Biographies}

Ali Saeidinezhad received his $\mathrm{PhD}$ in Mechanical Engineering at Yazd University, Yazd, Iran in 2015. $\mathrm{He}$ is currently a Lecturer at the Department of Mechanical Engineering, Islamic Azad University of Sirjan, Hijrat Blvd., Sirjan, Iran. His research interests are in the areas of aero-hydrodynamics, experimental aerodynamic, and centrifugal fan.

Ali Akbar Dehghan is currently a Professor of Mechanical Engineering at Yazd University, Yazd, Iran. He received his $\mathrm{PhD}$ in Mechanical Engineering from The University of New South Wales, Australia in 1994. His main research interests include experiments in fluid flow, aeroacoustics and energy, and exergy analysis of energy conversion systems. He has published around 60 papers in prestigious journals and more than 100 papers in national and international conferences. He has served as a reviewer in many international journals and supervised many $\mathrm{PhD}$ and master theses so far.

Mojtaba Dehghan Manshadi received his BS, MS, and $\mathrm{PhD}$ degrees in Aerospace Engineering from Sharif University of Technology in 2001, 2004, and 2009, respectively. He is currently an Associate Professor at the Department of Aerospace and Mechanical Engineering at Malek Ashtar University of Technology in Shahinshahr, Iran. His research interests include aerodynamic design and optimization, aero-hydrodynamics, applied computational fluid dynamics, and experimental aerodynamics. 